\title{
Evaluation of In-House Multiplex Polymerase Chain Reaction (MPCR) For Diagnosis of Pulmonary Tuberculosis
}

\author{
Authors \\ Mohammad Irfan', Dakshina Bisht ${ }^{2 *}$, Molly Madan ${ }^{3}$ \\ ${ }^{1}$ Ph.D Student, ${ }^{2}$ Professor \& Head of Department, Department Of Microbiology, Santosh Medical College, \\ Santosh University, Ghaziabad, Delhi NCR, India \\ ${ }^{3}$ Professor \& Head of Dept, Dept of Microbiology, Subharti Medical College, Meerut, UP, India \\ *Corresponding Author \\ Dr Dakshina Bisht \\ Professor \& Head of Department, Department of Microbiology, Santosh Medical College, \\ Santosh University, Ghaziabad- 201009, Delhi NCR., India \\ Email: dakshinabisht@hotmail.com,Tel:91-9810510852

\section{ABSTRACT} \\ Background: Diagnosis of tuberculosis is still an ongoing problem however nucleic acid amplification test \\ has emerged as a promising tool for its diagnosis. Single gene target may result in false negative due to the \\ absence or the presence of only few copies of target DNA in some M.tuberculosis isolates. The objective of \\ this study was to evaluate a multiplex PCR (MPCR) for the detection of M. tuberculosis in sputum samples. \\ Materials \& Methods: 150 clinically suspected cases of pulmonary tuberculosis were processed for detection \\ of mycobacterial infections by ZN staining smear examination, LJ culture and Multiplex PCR tests which \\ comprised of genus specific primer targeting insertion sequence 6110 (IS6110), MPB64 (23kDa) and Protein \\ $b(38 k D a)$.
}

Results: Multiplex PCR showed highest sensitivity of $100 \%$, followed by $65.2 \%$ for AFB smear when LJ culture was considered as gold standard. Conclusion: Multiplex PCR increased the sensitivity and it can be used to detect samples with M.tuberculosis strains lacking IS6110.

Keywords: Mycobacterium tuberculosis complex (MTBC), IS6110, MPB64, 38kDa (Pab b), Multiplex polymerase chain reaction (MPCR)

\section{INTRODUCTION}

One hundred and thirty three years after Robert koch recognized Mycobacterium tuberculosis (MTB) as the causative agent of tuberculosis (TB), it still poses an enormous global public health burden today ${ }^{1}$ World health organization (WHO) reported that there were an estimated 9.6 million new TB cases and 1.5 million TB deathsin $2014^{2}$. In India, incidence (all cases) was estimated to be 167 person per 100,000 population and the prevalence (all cases) was 195 person per 100,000 population ${ }^{2}$. However on the other hand, the detection rate for all TB cases was $74 \%^{2}$. The main concern about $\mathrm{TB}$ control in India and elsewhere is the rapid and 
sensitive diagnosis of the infection. In developing countries, the diagnosis of mycobacterial infection is not made timely leading to mismanagement and empirical therapeutic trials which gave rise to development of drug resistance ${ }^{3}$.

Although the conventional technique of direct smear examination is cheap and easy to perform, its low sensitivity is a major drawback ${ }^{1}$. On the other hand, the molecular-based diagnosis by polymerase chain reaction techniques is faster but accuracy is determined by the choice of the target DNA. The PCR methods has been used as an alternative that presents high sensitivity and specificity for the rapid diagnosis of infectious diseases. However, the use of PCR in thedetection of MTBC has produced varying results, especially in relation to the sensitivity of the test ${ }^{4,5,6}$. Various targets sequences such as insertion sequence IS6110, 65kDa (GroEL), $38 \mathrm{kDa}$ (PhoS, CIE Ag78 or Pab) and MPB64 $(23 \mathrm{kDa})$, have therefore been used. Among these IS6110 is more commonly used because of its repetitive sequence nature. This property helps increase the sensitivity of PCR over that obtained in the amplification of single DNA sequence ${ }^{7}$. However, the absence or the presence of only a few copies of this sequence has been reported in some strains particularly those from Southeast Asia ${ }^{8}$. A large number of clinical isolates of M.Tuberculosis from South India ${ }^{9}$ had either a single copy (40\%) or no copy (4\%) of IS6110. An alternative approach may be Multiplex Polymerase chain reaction (MPCR), in which several target genes for mycobacterium tuberculosis complex (MTBC) are amplified simultaneously to increase the sensitivity and specificity of the test (IS6110,MPB64 and Protein b). MPCR also has several strengths such as cost effectiveness and reduced possibility of PCR contamination ${ }^{10}$.

Effective tuberculosis control requires that patients be identified and placed on proper anti tuberculosis therapy. The rapid, sensitive and specific test for detection of mycobacterium has been a long standing need. Thus, we standardized and evaluate the multiplex polymerase chain (MPCR) utilizing multiple targets (Insertion Sequence 6110, MPB64 and $38 \mathrm{kDa} \mathrm{Pab}$ b.) for rapid detection of mycobacterium tuberculosis complex in routine diagnosis. The sensitivity and specificity of MPCR were compared with Ziehl-Neelsen (Z.N) staining microscopy and Lowenstein-Jensen culture.

\section{MATERIAL AND METHODS}

The study was performed in the Department of Microbiology, Santosh Medical College in collaboration with Subharti Medical College and was approved by institutional research ethics committee. A written consent was obtained from all patients who consented to provide sputum samples after understanding the objects and other details of the study.

Specimen Collection: Two consecutive sputum specimens (up to $5 \mathrm{ml}$ each), one spot and the other early morning, were collected from 150 clinically suspected tuberculosis individuals.

Acid fast staining: A direct smear was made from each sputum specimen and stained by the Z.N staining method ${ }^{11}$. Both the sample (spot and early morning) collected from each patients were pooled and were then processed for concentration.

Processing of sputum sample: An equal volume of $\mathrm{N}$-acetyle-L-cystein $\quad-\mathrm{NaOH} \quad(\mathrm{NALC}-\mathrm{NaOH})^{12}$ solution was added to the sputum sample and the content was shaken for 15-30 seconds and allowed to stand for 15 minutes. The digested/ decontaminated sputum sample was then diluted with phosphate buffer $(\mathrm{pH}$ 6.8) and centrifuged at $3600 \times \mathrm{g}$ for $15 \mathrm{mins}$ at room temperature. Supernatant was discarded in splash proof container. The sediment part was used for LJ culture as per standard protocol ${ }^{11}$ and for DNA extraction.

\section{Culture and recovery of Mycobacteria from} sputum samples: LJ media, widely used for tuberculosis diagnosis, was used as a baseline test to access the diagnostic accuracy of in -house multiplex PCR. From the sediment, inoculated two slopes of LJ medium ${ }^{11}$. The inoculated LJ culture 
bottle were incubated for up to 8 weeks with daily examination for first week and then weekly examination for evidence of growth. Colonies from culture positive L.J bottle were confirmed for presence of AFB by Z.N staining microscopy and biochemical tests.

Biochemical tests: The mycobacterial isolates obtained were subjected to niacin and heat-resistant catalase test to differentiate mycobacterium tuberculosis complex with nontuberculous mycobacteria $^{11}$.

DNA extraction: The sediment obtained after the decontamination method was subjected to DNA extraction. DNA was extracted using commercially available QIAmp DNA mini kit (QIAGEN) with one initial additional step. The sediment obtained after the processing of sputum sample were kept at $80^{\circ} \mathrm{C}$ for 15 minutes for inactivation of possible mycobacteria. And then further processed as per the manufacturer guidelines.

Multiplex PCR: The primer used in the MPCR were targeted to detect M.tuberculosis complex based on amplification of the DNA sequence of 123 bp from IS6110 ${ }^{13}, 240$ bp from MPB64 ${ }^{14}$ and 419 bp from $38 \mathrm{kDa}$ protein ${ }^{15}$. Table. 1 shows the oligonucleotide sequences used in the amplification. A $50 \mu 1$ reaction was setup containing 1.25 unit Taq DNA Polymerase, 1x Buffer $0.2 \mathrm{mM}$ dNTPs, $1.5 \mathrm{mM} \mathrm{MgCl}_{2}, 10 \mathrm{pmol}$ of each forward and reverse primer, extracted DNA sample and deionized water. Positive (H37Rv strain DNA) and negative control (Nuclease free water) run in each experiment. Applied Biosystem 2700 model of thermal cycler was used. Temperature cycling conditions include $94^{\circ} \mathrm{C}$ for $5 \mathrm{~min}$, followed by 30 cycles at $94^{\circ} \mathrm{C}$ for $30 \mathrm{sec}$, annealing of primers at $65^{\circ} \mathrm{C}$ for $45 \mathrm{sec}$ and primer extension at $72^{\circ} \mathrm{C}$ for $45 \mathrm{sec}$ and final extension at $72^{\circ} \mathrm{C}$ for $10 \mathrm{~min}$. The amplified product was stored at $4^{0} \mathrm{C}$ until separated on $1.5 \%$ agarose gels. The agarose gel was subsequently stained with ethidium bromide and visualized on a UV-light trans illuminator (Bangalore Genie, Bangalore,
India) to look for bands 123bp for IS6110, 240bp for MPB64 and 419bp for Protein b (Pab b) using a molecular marker of $100 \mathrm{bp}$ ladder. The sample showing the presence of all $123 \mathrm{bp}, 240 \mathrm{bp}$ and 419 bp band or any two or any one were considered positive.

Table 1: Oligonucleotide sequences used in multiplex polymerase Chain reaction assay

\begin{tabular}{|c|c|c|}
\hline $\begin{array}{l}\text { Oligo. } \\
\text { Name } \\
\text { (Gene } \\
\text { Target) }\end{array}$ & Primers Sequence 5'to 3' & $\begin{array}{l}\text { Expected } \\
\text { Amplicon } \\
\text { Size (bp) }\end{array}$ \\
\hline \multirow{2}{*}{ IS6110 } & $\begin{array}{l}\text { Forward CCT GCG AGC } \\
\text { GTA GGC GTC GG }\end{array}$ & \multirow{2}{*}{$123 \mathrm{bp}$} \\
\hline & $\begin{array}{l}\text { Reverse CTC GTC CAG } \\
\text { CGC CGC TTC GG }\end{array}$ & \\
\hline \multirow{2}{*}{ MPB64 } & $\begin{array}{l}\text { Forward TCC GCT GCC } \\
\text { AGT CGT CTT CC }\end{array}$ & \multirow{2}{*}{$240 \mathrm{bp}$} \\
\hline & $\begin{array}{l}\text { Reverse GTC CTC GCG } \\
\text { AGT CTA GGC CA }\end{array}$ & \\
\hline $\begin{array}{l}38 \mathrm{kDa} \\
\text { (Protein b) }\end{array}$ & $\begin{array}{lll}\text { Forward ACC ACC } & \text { GAG } \\
\text { CGG TTC GCC } & \text { TGA } \\
\text { ReverseGAT CTG CGG } \\
\text { GTC GTC CCA GGT }\end{array}$ & $419 b p$ \\
\hline
\end{tabular}

\section{STATISTICAL METHODS}

The sensitivity, specificity, positive predictive value and the negative predictive value were calculated using the standard formulae. LJ culture was considered as the base line test.

\section{RESULT}

Of the total 150 pulmonary tuberculosis suspected patients, 112 were males with an average age of 37.1 yrs. and 38 were female patients with an average age of 36.9 yrs. $86 \%$ had complained of cough more than two weeks. Clinical data of patients in Table 2 also shows that, $80 \%$ had body temperature of $\geq 37.5{ }^{0} \mathrm{C}$, chest pain $59 \%$ and loss of appetite $70 \%$. Overall, $19.3 \%$ spot specimens were positive by smear compared to $20.6 \%$ being smear positive in the early morning specimens. The specimens positive for smear collected at spot were also positive for specimens collected early in the morning. Sensitivity of the Z.N staining method was $67 \%$ whereas specificity was $100 \%$. The positive predictive value was $100 \%$ and the negative predictive value was $87.3 \%$ Table 3 . Sputum culture 
results showed $30.6 \%$ were found positive for growth of M.tuberculosis. All smear positive cases were also culture positive however, of the smear negative cases $12.6 \%$ were culture positive. Positivity rate of in-house MPCR was found to be the highest of all the diagnostic test used in this study. From 150 pulmonary suspects, $40.6 \%$ were detected with MTB complex. The MPCR test was found to have a much higher sensitivity of $100 \%$ and specificity $85.5 \%$. (LJ culture as Gold standard) whereas the positive predictive value was $75 \%$ and negative predictive value was $100 \%$. Table 3

Table 2 Demographic and clinical characteristics of patients.

\begin{tabular}{|l|l|l|}
\hline Demographic/Clinical & Total \\
\hline \multirow{3}{*}{ Sex } & Male & $112(74.6 \%)$ \\
\cline { 2 - 3 } & Female & $38(25.33 \%)$ \\
\hline \multirow{2}{*}{ Cough } & Male & 37.43 Years \\
\cline { 2 - 3 } & Female & 36.9 Years \\
\hline \multirow{3}{*}{ Fever } & $>2$ Weeks & $129(86.01 \%)$ \\
\cline { 2 - 3 } & $<2$ Weeks & $21(14.0 \%)$ \\
\hline Chest Pain & $>2$ Weeks & $120(80.0 \%)$ \\
\cline { 2 - 3 } Breathlessness & $<2$ weeks & $30(20.0 \%$ \\
\hline Hemoptysis & $89(59.3 \%$ \\
\hline History Of Contact & $33(22.01 \%)$ \\
\hline Loss Of Appetite & $28(18.6 \%)$ \\
\hline
\end{tabular}

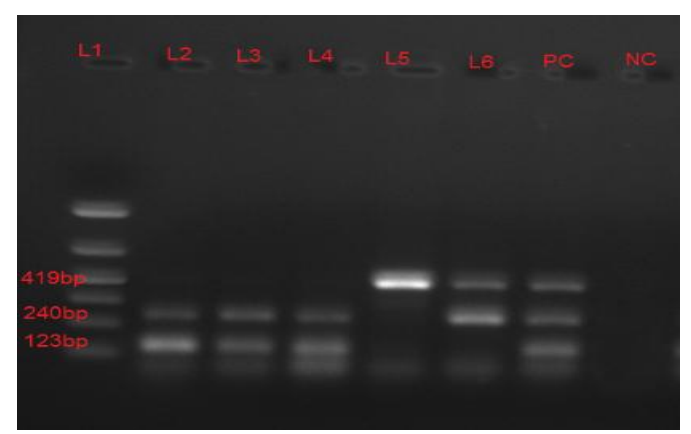

Figure 1: L1- 100bp Ladder, L2 to L4-Positive clinical sample with $123 \mathrm{bp}$ and $240 \mathrm{bp}$ band, L5Positive clinical sample with $419 \mathrm{bp}$ band only, L6Positive clinical sample with 240bp and 419 bp band. Lane PC -Positive control (H37Rv strain DNA) with all three 123bp IS6110, 240bp MPB64 and 419bp Pab b bands. And Lane NC-Negative control.
Table 3 Diagnostic Comparison between Morning Sputum Smear, MPCR \&Gold Standard Culture Test

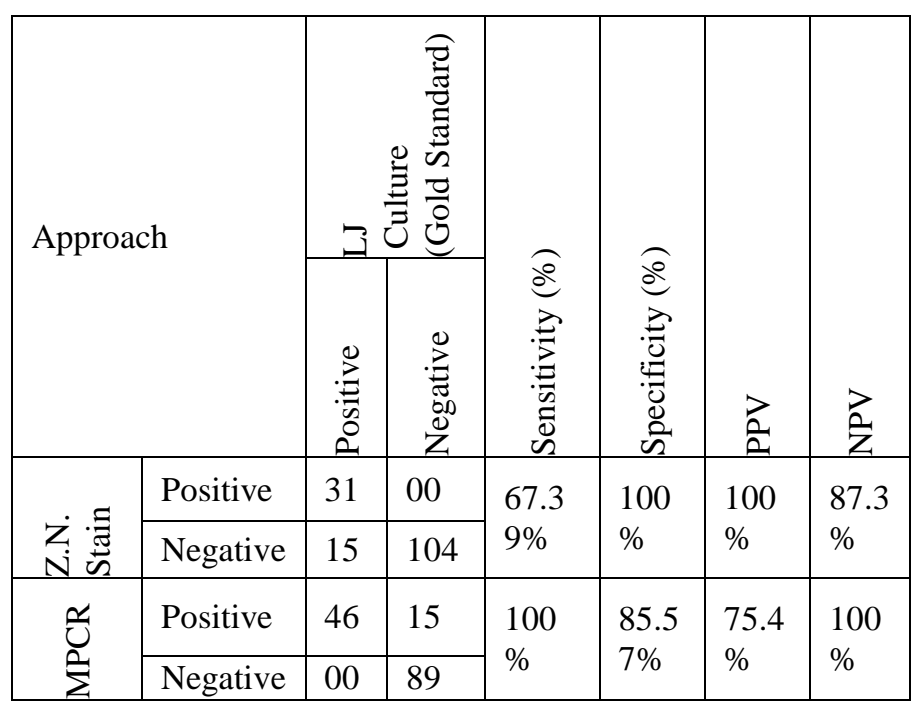

*PPV: Positive Predictive Value; NPV: Negative Predictive Value

\section{DISCUSSION}

Our result showed that, smear positivity rate was $20.6 \%$, which is almost similar to a studies conducted in India by Myneedu et $\mathrm{al}^{16}$, also in high prevalent countries like Nigeria and Ethiopia 21\%, Yemen $24 \%$ and Nepal $25 \%{ }^{17}$ where sputum were examined for diagnosis of tuberculosis. The available limited data on the yield of smear positivity by examining spot verses morning sputum suggests that yield of single morning specimen is approximately higher by $12 \%$ over the yield of single spot specimen ${ }^{18}$. Higher yield in morning samples were also documented by Mase et al in his research publication ${ }^{17}$. Sensitivity and specificity of smear examination method were $67.3 \%$ and $100 \%$ respectively (LJ culture as gold standard) which is comparable to a study conducted by Myneeduet $\mathrm{al}^{16}$ and Hirao et $\mathrm{al}^{19}$. LJ medium culture method, which is considered as gold standard of M.tuberculosis detection, recovered $30.6 \%$ positive sputum specimens. Our data confirm that culture positive result was $10 \%$ more than the result of smear microscopy. This is comparable to Myneeduet $\mathrm{al}^{16}$ whose findings confirmed that culture positive result was $13 \%$ more than the result of smear microscopy. Also, our data indicate that in the diagnosis of tuberculosis, culture had greater 
sensitivity than Z.N staining microscopy method, in case of a single specimen, the diagnostic value of culture is quite significant. But these traditional bacteriological methods are either slow or their sensitivity is quite low.

PCR method has been used as an alternative that presents high sensitivity and specificity for the rapid diagnosis of infectious diseases. However, successful use of DNA sequence for the detection of mycobacteria crucially depends on the right and logical choice of the target sequences, which ideally should be present in all mycobacterial complex. The use of PCR in the detection of mycobacterium tuberculosis has produced varying results, especially in relation to the sensitivity of the test ${ }^{4,5,6}$. Most previous studies have generally targeted IS6110 as it is present in multiple copies in the MTB genome ${ }^{20-24}$. Kent and colleagues claimed to demonstrate the existence of homology between an IS6110-derived probe and DNA isolated from a variety of nontuberculous mycobacteria ${ }^{25}$. Also, absence or presence of only a few copies of insertion sequence IS6110 has been reported. ${ }^{8,9}$ To overcome this problem we standardized and evaluated MPCR assay using three different gene i.e. IS6110, MPB64 and Pab b for detection of MTBC in sputum sample. Our study is unique in the fact that all genes were amplified together and were able to diagnose the cases which were missed by IS6110 alone or by MPB64 or Pab b in detection. MPCR method reduces errors, as well as cost and increases the sensitivity of the test ${ }^{10}$.

Our result showed that the sensitivity and specificity of MPCR test for diagnosis of MTBC in sputum sample was $100 \%$ and $85.5 \%$ respectively (L.J Culture as Gold standard) which is comparable to K. Sharma et al who achieved $100 \%$ sensitivity and $100 \%$ specificity in a retrospective study ${ }^{10}$. We also noted a higher sensitivity when compared to uniplex PCR. Seth et al evaluated a uniplex PCR using MPB64 as a target reported a sensitivity of $85 \%{ }^{26}$, Negi et al evaluated Pab b as a diagnostic target alone using a uniplex PCR in pulmonary samples and reported a sensitivity of $74 \%$ and specificity of $100 \%{ }^{27}$. MPCR method is not only a rapid and sensitive tool, but it also demands less skills. K Sharma et al, found that MPCR assay was as good as RT PCR ${ }^{10}$ in the detection of MTBC. MPCR could be used for patient care in endemic resource poor countries, where RT- PCR technologies is not feasible due to cost and complexity.

\section{CONCLUSIONS}

Molecular diagnosis of tuberculosis by MPCR with more than 2-3 target genes may have a great potential to improve the clinicians ability to diagnosis of TB. This will ensure early treatment to patients and prevent transmission of disease.

\section{ACKNOWLEDGEMENT- NONE CONFLICT OF INTEREST: NIL}

\section{REFERENCES}

1. Koch, R., 1882. Die Atiologic der Tuberkulose. Berl. Klin. Wochenschr. 15, 221-230.

2. Global Tuberculosis Report 2015, World Health Organization (WHO).

3. Centers for Disease Control and Prevention (CDC). (2002) Disseminated infection with simiae-avium group mycobacteria in persons with AIDS - Thailand and Malawi, 1997. MMWR Morb Mortal Wkly Rep 51, 501502.

4. García-Quintanilla A, Garcia L, Tudó G, Navarro M, González J, Anta MTJ. Singletube balanced heminested PCR for detecting Mycobacterium tuberculosis in smearnegative samples. J ClinMicrobiol 2000; 38:1166-9.

5. Montenegro SH, Gilman RH, Sheen P, Cama R, Caviedes L, Hopper $\mathrm{T}$, et al. Improved detection of Mycobacterium tuberculosis in Peruvian children by use of a heminested IS6110 polymerase chain reaction assay. Clin Infect Dis 2003; 36:1623.

6. Shingadia D, Novelli V. Diagnosis and treatment of tuberculosis in children. Lancet Infect Dis 2003; 3:624-32. 
7. Eisenach KD, Cave MD, Bates JH, Crawford JT. Polymerase chain reaction amplification of a repetitive DNA sequence specific for Mycobacterium tuberculosis. J Infect Dis 1990; 161:977-81.

8. Kerry H. Lok, Benjamin WH, Jr, Kimerling ME, Virgina Pruitt V, Lathan M, Razeq J, Nancy Hooper N, Cronin W, Dunlap NE (2002) Molecular differentiation of Mycobacterium tuberculosis strains without IS6110 insertions. Emerg Infect Dis 8: 1303-1305

9. Das S, Paramasivan CN, Lewis DB, Prabhakar R, Narayanan PR (1995) IS6110 restriction fragment length polymorphism typing of clinical isolates of mycobacterium tuberculosis from patients with pulmonary tuberculosis in Madras, South India, Tubercle Lung Dis 76: 550-554.

10. K Sharma et al. Evaluation of multiplex polymerase chain reaction utilizing multiple targets in mycobacterium tuberculosis direct test negative but culture positive Cases: A potential method for enhancing the diagnosis of tuberculosis. Indian journal of medical microbiology, (2013)31(4):370-373

11. Standard Operating Procedure For Mycobacteriology Laboratory 2010, Dept Of Bacteriology Tuberculosis Research Centre, ICMR, Mayor V.R. Ramanathan Road, Chetpet, Chennai, 6000 31, India

12. Bailey \& Scott's Diagnostic Microbiology, 12th Edition Procedure 45-1 Chapter 45 Mycobacteria 489

13. Eisenach KD, Cave MD, Bates JH, Crawfor JT. Polymerase chain reaction amplification of a repetitive DNA sequence specific for $M$. tuberculosis. J Infect Dis 1990;161:977-81.

14. Kusumsharma, suma B, Appannanavar, Manish Modi, Malkitsingh, amansharma, subhashvarma, Role Of Multiplex Polymerase Chain Reaction Using IS6110 And Protein B For The Diagnosis Of Extra Pulmonary Tuberculosis: North India. Indian journal of pathology and microbiology58(1), January-, arch 2015.
15. Sjobring U, Mecklenburg M, Andersen AB, Miorner H. Polymerase chain reaction for detection of Mycobacterium tuberculosis. J ClinMicorbiol1990;28:2200-4.

16. V.P Myneedu, A.K.Verma, P.P.Sharma and D.Behra. A Pilot study of same day sputum smear examination, its feasibility and usefulness in diagnosis of pulmonary TB. Indian journal of tuberculosis 2011;58:160167

17. Mase SR, Ramsay A, Ng V, Henry M, Hopewell PC et al. Yield of serial sputum specimen examinations in the diagnosis of pulmonary tuberculosis: a systematic review. Int j tuber Lung Dis 2007; 11: 485-95

18. Ramsay A, Md.Yassin A, Cambanis A, Hirao S, Almotawa A, MdGammo, Lawson L, Arbide I, Al-Aghbari N, Al-Sonboli N, Sherchand JB, Gauchan P and Cuevas LE. Front-Loading Sputum Microscopy Services: An Opportunity To Optimize Smear Based Case Detection Of Tuberculosis In High Prevalence Countries. J Trop Med 2009;10.1155: 1-6

19. Hirao S, Yasin MA, Khaofu HG, Lawson L Cambanis A, Ramsay A Cuevas LE. Sameday smear in the diagnosis of tuberculosis. Trop med \&intr health 2007;12:1459-63.

20. Negi SS, Anand R, Pasha ST, Gupta S, Basir SF, Khare S, Lal S (2007) Diagnostic potential of IS6110,38kDa and $85 \mathrm{~B}$ sequence Based polymerase Chain reaction in the diagnosis of M.Tuberculosis in clinical samples. India $\mathrm{J}$ Med Microbiol 25:43-49.

21. Ashok Rattan (2000) PCR for diagnosis of tuberculosis: where are we now? Indian $\mathrm{J}$ Tuberculosis47:79-82.

22. Keshwarwani RC, Pandey A, Mishra A, Singh A (2004) Polymerase chain reaction (PCR): its comparison with conventional Techniques for diagnosis of extra pulmonary tuberculosis diseases. Indian J Surg 66:8488. 
23. Clarridge JE, Shawar RM, Shinnick TM, Plikaytis BB (1993) Large scale use of polymerase chain reaction for detection of M.Tuberculosis in routine mycobacteriology laboratory. J ClinMicrobiol 31:2049-2056

24. Sekar B, Selvaraj L, Alexis A, Ravi S, Arunagiri K, Rathinavel L (2008) The utility of IS6110 sequence based polymerase chain reaction in comparison to conventional methods in the diagnosis of extra pulmonary tuberculosis. Indian J Med Microbiol 26:

25. Kent, L., T. D. McHugh, O. Billington, J. W. Dale, and S. H. Gillespie. 1995. Demonstration of homology between IS6110 of Mycobacterium tuberculosis and DNAs of other Mycobacterium spp. J. Clin. Microbiol. 33:2290- 2293.

26. Seth P, Ahuja GK, Bhanu NV, Behari M, Bhowmik S, Broor S, et al. Evaluation of polymerase chain reaction for rapid diagnosis of clinically suspected tuberculous meningitis. Tuber Lung Dis 1996;77:353-7.

27. Negi SS, Anand R, Basir SF, Pasha ST, Gupta S, Khare S, et al. Protein antigen b $(\mathrm{Pab})$ based PCR test in diagnosis of pulmonary and extra-pulmonary tuberculosis. Indian J Med Res 2006;24:8 